\title{
Total knee arthroplasty after high tibial osteotomy. A systematic
} review

\author{
Tom M van Raaij*1,2, Max Reijman ${ }^{1}$, Andrea D Furlan ${ }^{3,4}$ and Jan AN Verhaar ${ }^{1}$
}

Address: ${ }^{1}$ Department of Orthopaedics, Erasmus University Medical Center, Rotterdam, the Netherlands, ${ }^{2}$ Department of Orthopaedics, Martini Hospital, Groningen, the Netherlands, ${ }^{3}$ Institute for Work \& Health, Toronto, Canada and ${ }^{4}$ Toronto Rehabilitation Institute, Toronto, Canada

Email: Tom M van Raaij* - t.m.vanraaij@mzh.nl; Max Reijman - m.reijman@erasmusmc.nl; Andrea D Furlan - afurlan@iwh.on.ca; Jan AN Verhaar - j.verhaar@erasmusmc.nl

* Corresponding author

Published: 20 July 2009

BMC Musculoskeletal Disorders 2009, 10:88 doi:10.1 186/147I-2474-10-88
Received: 13 November 2008

Accepted: 20 July 2009

This article is available from: http://www.biomedcentral.com/147/-2474/I0/88

(C) 2009 van Raaij et al; licensee BioMed Central Ltd.

This is an Open Access article distributed under the terms of the Creative Commons Attribution License (http://creativecommons.org/licenses/by/2.0), which permits unrestricted use, distribution, and reproduction in any medium, provided the original work is properly cited.

\begin{abstract}
Background: Previous osteotomy may compromise subsequent knee replacement, but no guidelines considering knee arthroplasty after prior osteotomy have been developed. We describe a systematic review of non-randomized studies to analyze the effect of high tibial osteotomy on total knee arthroplasty.

Methods: A computerized search for relevant studies published up to September 2007 was performed in Medline and Embase using a search strategy that is highly sensitive to find nonrandomized studies. Included were observational studies in which patients had total knee arthroplasty performed after prior high tibial osteotomy. Studies that fulfilled these criteria, were assessed for methodologic quality by two independent reviewers using the critical appraisal of observational studies developed by Deeks and the MINORS instrument. The study characteristics and data on the intervention, follow-up, and outcome measures, were extracted using a pre-tested standardized form. Primary outcomes were: knee range of motion, knee clinical score, and revision surgery. The grade of evidence was determined using the guidelines of the GRADE working group.

Results: Of the 458 articles identified using our search strategy, 17 met the inclusion criteria. Fifteen studies were cohort study with a concurrent control group, one was a historical cohort study and one a case-control study. Nine studies scored $50 \%$ or more on both methodological quality assessments. Pooling of the results was not possible due to the heterogeneity of the studies, and our analysis could not raise the overall low quality of evidence. No significant differences between primary total knee arthroplasty and total knee arthroplasty after osteotomy were found for knee range of motion in four out of six studies, knee clinical scores in eight out of nine studies, and revision surgery in eight out of eight studies after a median follow-up of 5 years.
\end{abstract}

Conclusion: Our analysis suggests that osteotomy does not compromise subsequent knee replacement. However, the low quality of evidence precludes solid clinical conclusions.

\section{Background}

High tibial osteotomy (HTO) is an accepted surgical treatment of medial unicompartmental osteoarthritis (OA) of the knee with varus mal-alignment in young patients. However, there is no sound evidence that an osteotomy is more effective than alternative non-operative therapies, 
such as valgus bracing or laterally wedged insoles [1]. Furthermore, results seem to deteriorate with time and this group of patients may require total knee replacement [2]. Success of primary total knee arthroplasty (TKA) with knee osteoarthritis is well established, and about $85 \%$ of patients are satisfied with the surgical outcome [3]. When considering osteotomy in the early treatment of medial compartment knee OA, subsequent TKA should not be compromised, and results should not deteriorate more rapidly than after primary TKA alone [4]. In the past, there have been reports of technical difficulties after failed HTO that influenced outcomes of knee replacement; however these studies were criticized due to patient selection bias $[5,6]$.

The aim of this study was to collect the best available scientific evidence from clinical studies examining TKA after HTO compared with primary TKA, and determine whether an osteotomy influences clinical outcome after TKA. Although randomized controlled trials (RCT) are considered the ideal and highest level of evidence in making decisions about the care of individual patients, numerous "good" surgical practices have evolved into "standard of care" without being randomized against placebo or ineffective treatment options [7]. This probably explains why no RCT has been published on the effect of TKA with previous HTO or not, and that high-quality observational studies constitute the best available evidence [8]. We conducted a systematic review of non-randomized studies to analyze the effect of HTO on subsequent TKA, which may help facilitate the decisionmaking on performing osteotomy in the younger individual.

\section{Methods \\ Identification of studies}

A search of all relevant studies published in Medline and Embase up to September 2007 was performed to identify those investigating TKA after earlier HTO. The search strategy combined all phases of the optimal non-randomized studies strategy and used fixed method B, based on the study of Furlan et al. [9]. Key words used were: arthroplasty, replacement, knee, and osteotomy, and cohort studies (or controlled study, or follow-up studies, or prospective studies, or risk factors, or cohort.mp, or compared.mp, or groups.mp or multivariate.mp). Finally, all the references in the identified studies were checked to detect any additional published data.

Two reviewers (TR, MR) assessed the studies and whether they met the following inclusion criteria:

- patients in the study had TKA performed after prior HTO;
- the study had an observational design between 4 and 7 using the taxonomy of study designs described by Deeks et al. (controlled before-and-after, concurrent cohort, historical cohort, or case-control studies) [10];

- the article was written in English, German, or Dutch;

- full text was available for the article;

Disagreements on inclusion were resolved by discussion, and the final decision of a third reviewer (JV) was not necessary.

\section{Methodologic quality}

Two reviewers (TR, MR) assessed the methodologic quality independently from each other. In order to avoid conflict of interest two other reviewers (RB, DM) re-assessed one study that was (Co)-authored by TR and MR [11]. The critical appraisal of observational studies tool (Deeks) [10] and the methodological index for non-randomized studies (MINORS) form [12] were used. Disagreements were resolved in a consensus meeting. The maximum quality score was 12 for both forms. The measure of agreement between the two reviewers (TR, MR) is presented as kappa. The methodologic quality was used as an additional criterion for inclusion, and studies had to be of high quality to be selected for final review. High quality was based on a summary quality score, and defined as presenting an adequate concurrent cohort study that fulfilled $50 \%$ or more of the validity criteria on both quality instruments [13].

\section{Data extraction}

Two reviewers (TR, MR) independently extracted the study characteristics and data on the intervention (operation time, lateral ligamental release, tuberosity osteotomy, tibial component insert), clinical outcome measures (postoperative knee range of motion (ROM) and clinical knee scores), and revision surgery (aseptic loosening, patellar loosening, deep infection, miscellaneous), using a pre-tested standardized form. Agreement on data extraction was reached by consensus.

\section{Evidence synthesis}

The grade of evidence was determined following the guidelines of the GRADE (Grading of Recommendations, Assessment, Development, and Evaluation) working group [14]. GRADE acknowledges the primacy of RCT, but in addition recognizes circumstances in which highquality observational studies generate high-quality evidence of treatment effects [15]. Grades of evidence are divided into the following categories: high, moderate, low, and very low; randomized trials are considered of high, observational studies of low, and any other evidence of very low quality. The similarity of estimates of effect 
across studies (consistency), and the extent to which people, interventions, and outcome measures are similar to those of interest (directness) may lower or raise the grade of evidence. We judged that quality of life of patients receiving knee arthroplasty will mostly be affected by knee function, pain, and adverse events such as aseptic loosening or infection, and considered postoperative ROM, postoperative knee scores and revision surgery as critical outcome measurements. The lowest quality of evidence for any of the outcomes was used for rating overall quality of evidence, as suggested by the GRADE working group. The data for this review were collected and analyzed in compliance with the procedures and policies set forth by the Helsinki Declaration.

\section{Results \\ Included studies}

Of the 458 articles identified using our search strategy, 17 met the inclusion criteria (Table 1) [4-6,11,16-28]. After the methodological quality assessment nine studies scored $50 \%$ or more on both quality scores and were included in this review: van Raaij [11]; Haslam [4]; Huang [16]; Karabatsos [17]; Meding [18]; Haddad [19]; Nizard [20]; Amendola [21] and Mont [22]. The mean score was 7.6 (range, $6-9$ ) for the Deeks tool and corresponded with a $63 \%$ score. For the MINORS form the mean score was 7.1 (range, $6-8$ ) and corresponded with a 59\% score. The measure of agreement (kappa) between the two reviewers (TR, MR) was 0.86 for the Deeks tool quality score, and 0.95 for the MINORS form quality score. Disagreement occurred mainly because of reading errors and differences in interpretation of the comparability of group criteria.

For the nine studies included, all studies had a follow-up matched (for at least three characteristics) pair comparison design. An overview of the characteristics is presented in Table 2. There were a total of 371 TKAs with previous HTO compared to 369 primary TKAs. A lateral closing wedge technique was used in four studies, one study presented results after valgus dome osteotomy, and four studies described combined or unknown osteotomy techniques. Osteotomy delayed TKA with a median of 7 $(5-10)$ years. In one study patients served as their own controls when receiving bilateral knee replacement after unilateral HTO. One study presented two comparison groups; one was matched by pre-TKA deformity and the other by pre-HTO deformity. All populations, but one (59 years), had a mean age beyond 60 years at TKA surgery. Four studies contained more women than men; between 89 and $100 \%$ of patients were diagnosed with knee osteoarthritis. All studies reported on primary knee prosthesis designs, and the use of revision tibial components was not mentioned. Seven studies presented all cemented TKAs in almost all cases $(94-100 \%)$. Only one study described a singular prosthesis design. Patella replacement was mentioned in four studies; in two studies all patients received patellar resurfacing, in one study about half of the patients, and in one study approximately $10 \%$ of the patients. The average follow-up after TKA was at least three years in all studies; with a median follow-up of $5(3-13)$ years.

Table I: Identified observational studies reviewed for design and quality

\begin{tabular}{|c|c|c|c|c|c|}
\hline & \multicolumn{3}{|c|}{ Design } & \multicolumn{2}{|c|}{ Quality assessment } \\
\hline & study & Year & Deeks classification & Deeks tool & Minors list \\
\hline I & van Raaij [II] & 2007 & concurrent cohort (5) & 9 & 8 \\
\hline 2 & Haslam [4] & 2007 & concurrent cohort (5) & 8 & 7 \\
\hline 3 & Huang [16] & 2002 & concurrent cohort (5) & 7 & 7 \\
\hline 4 & Karabatsos [17] & 2002 & concurrent cohort (5) & 7 & 7 \\
\hline 5 & Meding [18] & 2000 & concurrent cohort (5) & 8 & 7 \\
\hline 6 & Haddad [19] & 2000 & concurrent cohort (5) & 8 & 7 \\
\hline 7 & Nizard [20] & 1998 & concurrent cohort (5) & 8 & 7 \\
\hline 8 & Amendola [2I] & 1998 & concurrent cohort (5) & 6 & 6 \\
\hline 9 & Mont [22] & 1994 & concurrent cohort (5) & 7 & 8 \\
\hline 10 & Parvizi [5] & 2003 & concurrent cohort (5) & 5 & 9 \\
\hline 11 & Walther [23] & 2000 & concurrent cohort (5) & 4 & 4 \\
\hline 12 & Toksvig-Larsen [24] & 1998 & concurrent cohort (5) & 6 & 4 \\
\hline 13 & Bergenudd [25] & 1997 & concurrent cohort (5) & 6 & 5 \\
\hline 14 & Gill [26] & 1995 & concurrent cohort (5) & 5 & 4 \\
\hline 15 & Jackson [27] & 1994 & case-control (7) & 3 & 2 \\
\hline 16 & Windsor [6] & 1988 & historical cohort (6) & 3 & 4 \\
\hline 17 & Katz [28] & 1987 & concurrent cohort (5) & 5 & 6 \\
\hline
\end{tabular}

Those articles were selected with high quality on both instruments ( $\geq 50 \%$ or $\geq 6$ points) 
Table 2: Baseline characteristics of the 9 reviewed manuscripts

\begin{tabular}{|c|c|c|c|c|c|c|c|c|c|c|c|}
\hline $\begin{array}{l}\text { author, } \\
\text { year }\end{array}$ & & $\begin{array}{c}\text { eligible } \\
\text { knees, } \mathrm{N}\end{array}$ & $\begin{array}{l}\text { knees lost to } \\
\text { follow-up, } N\end{array}$ & $\begin{array}{l}\text { included } \\
\text { patients, N }\end{array}$ & TKA, N & women, \% & OA,\% & $\begin{array}{c}\text { time bought } \\
\text { by HTOt, } \\
\text { years }\end{array}$ & $\begin{array}{l}\text { age at } \\
\text { TKA } t \text {, } \\
\text { years }\end{array}$ & $\begin{array}{l}\text { follow-upt, } \\
\text { years }\end{array}$ & $\begin{array}{l}\text { patients } \\
\text { with } \\
\text { missing } \\
\text { data, N }\end{array}$ \\
\hline \multirow{2}{*}{$\begin{array}{l}\text { Van Raaij, } \\
2007 \text { [II] }\end{array}$} & HTO & 18 & 4 & 12 & 14 & 83 & 100 & 4.8 & 60 & 3.7 & 0 \\
\hline & control & 342 & - & 12 & 14 & 83 & 100 & NA & 61 & 4.0 & 0 \\
\hline \multirow{2}{*}{$\begin{array}{l}\text { Haslam, } \\
2007 \text { [4] }\end{array}$} & HTO & 78 & 27 & 40 & 51 & 48 & 100 & 4.8 & 65 & 12.6 & 0 \\
\hline & control & - & - & 44 & 51 & 48 & 100 & NA & 65 & 12.6 & 0 \\
\hline \multirow{2}{*}{$\begin{array}{l}\text { Huang, } \\
2002 \text { [16] }\end{array}$} & HTO & - & - & 15 & 17 & 87 & 100 & 8 & 61 & 5 & 0 \\
\hline & control & - & - & 14 & 17 & 86 & 100 & NA & 62 & 5 & 0 \\
\hline \multirow{2}{*}{$\begin{array}{l}\text { Karabatsos, } \\
2002 \text { [17] }\end{array}$} & HTO & - & - & 20 & 22 & 50 & 95 & 8.4 & 59 & 5.2 & 3 \\
\hline & control & - & - & 20 & 21 & 50 & 95 & NA & 60 & 4.7 & 3 \\
\hline \multirow{2}{*}{$\begin{array}{l}\text { Meding, } \\
2000[18]^{\mathrm{a}}\end{array}$} & HTO & 39 & - & 39 & 39 & 31 & 97 & 8.7 & 67 & 7.5 & 0 \\
\hline & control & 39 & - & 39 & 39 & 31 & 97 & NA & 67 & 6.8 & 0 \\
\hline \multirow{2}{*}{$\begin{array}{l}\text { Haddad, } \\
2000 \text { [19] }\end{array}$} & HTO & 50 & 0 & 42 & 50 & 62 & 100 & 7.3 & 65 & 6.2 & 2 \\
\hline & control & - & - & 42 & 50 & 57 & 100 & NA & 66 & - & 1 \\
\hline \multirow{2}{*}{$\begin{array}{l}\text { Nizard, } \\
1998 \text { [20] }\end{array}$} & HTO & 63 & 6 & 55 & 63 & 85 & 100 & 9.7 & 72 & 4.5 & 5 \\
\hline & control & 537 & - & - & 63 & 78 & 100 & NA & 71 & 4.0 & - \\
\hline \multirow{2}{*}{$\begin{array}{l}\text { Amendola, } \\
1998 \text { [21] }\end{array}$} & HTO & 42 & - & 39 & 42 & 36 & 100 & 5.4 & 64 & 3.1 & - \\
\hline & control & 168 & - & 39 & 41 & 49 & 100 & NA & 65 & 3.1 & - \\
\hline \multirow{3}{*}{$\begin{array}{l}\text { Mont, } 1994 \\
\text { [22] }\end{array}$} & HTO & 80 & 7 & 73 & 73 & 49 & 89 & 5 & 62 & 6.1 & 0 \\
\hline & control I b & 974 & - & 73 & 73 & 49 & 89 & NA & 64 & 6.0 & 0 \\
\hline & control II c & 974 & - & 73 & 73 & 49 & 88 & NA & 64 & 6.2 & 0 \\
\hline
\end{tabular}

$\mathrm{NA}=$ not applicable

- = not mentioned in manuscript

$t=$ the values are given as the average

$\mathrm{a}=$ patient group received bilateral TKA after unilateral $\mathrm{HTO}$ and served as own control

$\mathrm{b}=$ matched for pre-TKA deformity (within $5^{\circ}$ )

$c=$ matched for pre-HTO deformity (only varus knees)

\section{Study results}

Intra-operative results are shown in Table 3. Four studies reported on operation time, which in three studies was significantly prolonged (median of 26 minutes) for patients receiving TKA after prior osteotomy (index group) compared with primary TKA (control group). In seven studies more lateral ligamental releases (median of 6 ) were necessary in the index group in comparison to the control group. Significant differences were found in two studies. Two studies found that more tibial tuberosity osteotomies were performed in the index group, and one of the studies noted a significant difference. No significant differences were reported in the distribution for thickness of the tibial inserts in two studies. The postoperative ROM (Table 4) was mentioned in six studies, and these studies detected less knee motion for the index group with a median of $10^{\circ}\left(4^{\circ}-14^{\circ}\right)$ in comparison to the control group. Two studies noted significant differences. All studies presented a knee score (Table 4) which contained pain and function evaluation; Hospital for Special Surgery score (HSS) in five studies, Knee Society clinical rating system score (KSS) in five studies, Western Ontario and McMaster University Osteoarthritis Index (WOMAC) in two studies, and the Baltimore knee score in one study. HSS and WOMAC scores were less favorable for the index group. All these differences, however, were not significant. Although the KSS knee score of the index group was lower in four out of five studies, only one study reported a KSS knee score significantly lower than the control group. The KSS function score of the index group was higher in three out of five studies, but no significant differences were found. One study used the Baltimore Knee score and detected a result in the index group significantly inferior to the control group. All studies but one reported on revision surgery after TKA (Table 5). In eight studies no significant differences between both groups were described for aseptic loosening, deep infection or other additional interventions. Seven studies reported on patellar loosen- 
Table 3: Intraoperative results for TKA with - compared to without prior HTO for the 9 reviewed manuscripts

\begin{tabular}{|c|c|c|c|c|c|c|}
\hline author, year & & TKA, N & operation time, minutes & $\begin{array}{c}\text { lateral ligamental } \\
\text { release }\end{array}$ & $\begin{array}{c}\text { tibial tuberosity } \\
\text { osteotomy }\end{array}$ & tibial component insert \\
\hline \multirow[t]{2}{*}{ van Raaij, 2007 [II] } & HTO & 14 & 120 & 3 & I & $10 \mathrm{~mm}$ \\
\hline & control & 14 & 115 & 0 & 0 & $8 \mathrm{~mm}$ \\
\hline \multirow[t]{2}{*}{ Haslam, 2007 [4] } & HTO & 51 & - & - & - & - \\
\hline & control & 51 & - & - & - & - \\
\hline \multirow[t]{2}{*}{ Huang, 2002 [16] } & HTO & 17 & $168 \mathrm{a}$ & 5 & - & - \\
\hline & control & 17 & $142^{a}$ & 0 & - & - \\
\hline \multirow[t]{2}{*}{ Karabatsos, 2002 [17] } & НTO & 22 & $170 \mathrm{~b}$ & $7 c$ & - & - \\
\hline & control & 21 & $118^{b}$ & $2^{c}$ & - & - \\
\hline \multirow[t]{2}{*}{ Meding, 2000 [18] } & HTO & 39 & - & 4 & - & - \\
\hline & control & 39 & - & 1 & - & - \\
\hline \multirow[t]{2}{*}{ Haddad, 2000 [19] } & HTO & 50 & 23 min longer $d$ & 22 & - & difference; NS \\
\hline & control & 50 & - & - & - & \\
\hline \multirow[t]{2}{*}{ Nizard, 1998 [20] } & HTO & 63 & - & $15 \mathrm{e}$ & $7^{f}$ & - \\
\hline & control & 63 & - & $\mathrm{le}$ & if & - \\
\hline \multirow[t]{2}{*}{ Amendola, 1998 [21] } & HTO & 42 & - & 6 & - & - \\
\hline & control & 41 & - & 2 & - & - \\
\hline \multirow[t]{2}{*}{ Mont, 1994 [22] } & HTO & 73 & - & - & - & - \\
\hline & control & 73 & - & - & - & - \\
\hline
\end{tabular}

- = not mentioned in manuscript

${ }^{\text {a }} \mathrm{p}=0.002,{ }^{\mathrm{b}} \mathrm{p}<0.0001,{ }^{\mathrm{c}} \mathrm{p}=0.0089,{ }^{\mathrm{d}} \mathrm{p}<0.02,{ }^{\mathrm{e}} \mathrm{p}=0.0001,{ }^{\mathrm{f}} \mathrm{p}=0.03$

NS = no significant difference after TKA with - compared to without prior HTO

Table 4: Postoperative outcome measures after TKA with - compared to without prior HTO for the 9 reviewed manuscripts.

\begin{tabular}{|c|c|c|c|c|c|c|c|c|}
\hline author, year & & patients, $\mathrm{N}$ & knee range of motion, ${ }^{\circ}$ & HSS & KSS knee & KSS function & WOMAC & $\begin{array}{l}\text { Baltimore knee score; } \\
\text { excellent/good, \% }\end{array}$ \\
\hline \multirow[t]{2}{*}{ van Raaij, 2007 [I I] } & HTO & 12 & 110 & 79 & 79 & 70 & NS & - \\
\hline & control & 12 & 120 & 82 & 90 & 80 & & - \\
\hline \multirow[t]{2}{*}{ Haslam, 2007 [4] } & HTO & 40 & 91 a & 79 & - & - & - & - \\
\hline & control & 44 & $106^{a}$ & 80 & - & - & - & - \\
\hline \multirow[t]{2}{*}{ Huang, 2002 [16] } & НTO & 15 & - & - & 83 & 75 & - & - \\
\hline & control & 14 & - & - & 85 & 72 & - & - \\
\hline \multirow[t]{2}{*}{ Karabatsos, 2002 [17] } & HTO & 17 & - & - & - & - & NS & - \\
\hline & control & 17 & - & - & - & - & & - \\
\hline \multirow[t]{2}{*}{ Meding, 2000 [18] } & HTO & 39 & 113 & - & 89 & 81 & - & - \\
\hline & control & 39 & 118 & - & 90 & 84 & - & - \\
\hline \multirow[t]{2}{*}{ Haddad, 2000 [19] } & HTO & 40 & 93 & 87 & 91 & 70 & - & - \\
\hline & control & 41 & 103 & 89 & 89 & 66 & - & - \\
\hline \multirow[t]{2}{*}{ Nizard, 1998 [20] } & HTO & 50 & 101 & 79 & $74^{b}$ & 67 & - & - \\
\hline & control & - & 105 & 83 & $8 I^{b}$ & 64 & - & - \\
\hline \multirow[t]{2}{*}{ Amendola, 1998 [2I] } & HTO & 39 & $101^{c}$ & 86 & - & - & - & - \\
\hline & control & 39 & $115^{c}$ & 89 & - & - & - & - \\
\hline \multirow[t]{3}{*}{ Mont, 1994 [22] } & HTO & 73 & - & - & - & - & - & $47 \mathrm{~d}, \mathrm{e}$ \\
\hline & control I & 73 & - & - & - & - & - & $64 d$ \\
\hline & control II & 73 & - & - & - & - & - & 68 e \\
\hline
\end{tabular}

Follow-up time on a median of 5 years.

HSS = Hospital for Special Surgery score (maximum 100 points)

KSS $=$ Knee Society clinical rating system score (maximum 100 points)

WOMAC = Western Ontario and McMaster University Osteoarthritis Index

- = not mentioned in manuscript

NS = no significant difference after TKA with - compared to without prior HTO

${ }^{a} \mathrm{p}=0.006,{ }^{\mathrm{b}} \mathrm{p}=0.0001,{ }^{\mathrm{c}} \mathrm{p}<0.005,{ }^{\mathrm{d}} \mathrm{p}<0.01,{ }^{\mathrm{e}} \mathrm{p}<0.001$ 
ing and found no significant differences between the index and control groups. One study commented on staged patellar re-surfacing for persistent patellofemoral symptoms, and described no differences between both groups.

\section{Grade of evidence}

No important inconsistencies among the nine studies were found in the direction of effect and the size of differences in effect; prolonged operation time, extra operative procedures, less postoperative knee ROM, and no increase of revision surgery was noticed for patients receiving TKA after prior HTO in the studies reflecting on the aforementioned outcomes. All studies described patients in their $6^{\text {th }}$ or $7^{\text {th }}$ decade of life receiving TKA because of symptomatic knee osteoarthritis. Knee replacement, regardless of prosthesis type, has more or less the same relative effects across most patients, therefore we judged the evidence obtained as direct [29]. Table 6 shows the overall quality assessment of the grade of evidence of the nine high-quality observational studies comparing TKA with - to TKA without prior HTO. We found no strong association among the studies and the overall quality of evidence, therefore, remained low.

\section{Discussion}

Patients who require TKA for a failed HTO comprises a significant portion of those patients undergoing TKA [22]. Previous surgery may influence subsequent knee replacement, but so far, no guidelines considering TKA after prior osteotomy have been developed, and no grading of existing evidence has been determined. To our knowledge the present study is the first systematic review of existing literature on this topic. We used a limited search strategy in finding relevant non-randomized studies. Earlier Furlan et al. showed that the sensitivity of limited search strategies for a fixed set of controlled vocabulary and text words was between 95 and 100\% [9]. We assessed the quality of the retrieved studies with established forms, and we found good interobserver agreement for both the Deeks tool and MINORS form (kappa 0.86 and 0.95 ; respectively).

Well-designed observational studies may provide high quality of evidence in circumstances described by the GRADE working group. The present study, however, could not raise the current low quality level of evidence. All studies presented relative small sample sizes, and pooling of the data would have provided a more precise association with the clinical outcomes. The heterogeneity of the studies, mainly due to differences in gender, osteotomy techniques, and time of follow-up, made quantitative pooling of the data impossible and a systematic review represented the best available method to synthesize the current literature [30]. This obviously limits the validity of the conclusions that can be extracted form this analysis.

Surgical methods have been recognized to be important factors in the longevity of knee implants [31]. Subperiosteal exposure of the proximal tibia and eversion of the patellar mechanism are more difficult in the post-osteotomy knee due to soft tissue scaring. Ligamentous imbalance may also compromise the implant procedure. Seven studies reported that more lateral ligamental releases were necessary for the post-osteotomy patients, and two studies

Table 5: Revision surgery after TKA with - compared to without prior HTO for the 9 reviewed manuscripts.

\begin{tabular}{|c|c|c|c|c|c|c|}
\hline author, year & & TKA, N & aseptic loosening, $\mathrm{N}$ & patellar loosening, $\mathrm{N}$ & deep infection, $\mathrm{N}$ & other, $\mathrm{N}$ \\
\hline \multirow[t]{2}{*}{ van Raaij, 2007 [II] } & HTO & 14 & 0 & 0 & 0 & 2 \\
\hline & control & 14 & 0 & 0 & 1 & 2 \\
\hline \multirow[t]{2}{*}{ Haslam, 2007 [4] } & HTO & 51 & 4 & 1 & 0 & 0 \\
\hline & control & 51 & 2 & 0 & 0 & I \\
\hline \multirow[t]{2}{*}{ Huang, 2002 [16] } & HTO & 17 & 0 & 0 & 0 & 6 \\
\hline & control & 17 & 0 & 2 & 0 & 4 \\
\hline \multirow[t]{2}{*}{ Karabatsos, 2002 [17] } & HTO & 22 & 0 & 0 & 0 & 0 \\
\hline & control & 21 & 0 & 0 & 0 & 1 \\
\hline \multirow[t]{2}{*}{ Meding, 2000 [18] } & HTO & 39 & 1 & 3 & 0 & 2 \\
\hline & control & 39 & 0 & 1 & 0 & 2 \\
\hline \multirow[t]{2}{*}{ Haddad, 2000 [19] } & HTO & 50 & 1 & - & I & 11 \\
\hline & control & 50 & I & - & 2 & 8 \\
\hline \multirow[t]{2}{*}{ Nizard, 1998 [20] } & HTO & 63 & 0 & 1 & 0 & 13 \\
\hline & control & 63 & 0 & 0 & 0 & 10 \\
\hline \multirow[t]{2}{*}{ Amendola, 1998 [21] } & HTO & 42 & 0 & 1 & 0 & 3 \\
\hline & control & 41 & 1 & 0 & 0 & 0 \\
\hline \multirow[t]{2}{*}{ Mont, 1994 [22] } & HTO & 73 & - & - & - & - \\
\hline & control & 73 & - & - & - & - \\
\hline
\end{tabular}

Follow-up time on a median of 5 years.

- = not mentioned in manuscript 
Table 6: Quality assessment of the grade of evidence of the observational studies comparing TKA with - and without prior HTO

\begin{tabular}{|c|c|c|c|c|c|c|c|c|c|}
\hline \multirow[b]{3}{*}{ No of studies } & \multirow[b]{3}{*}{ Design } & \multirow{2}{*}{\multicolumn{3}{|c|}{ Quality assessment }} & \multirow{2}{*}{\multicolumn{2}{|c|}{ No of knees }} & \multicolumn{3}{|c|}{ Summary of findings } \\
\hline & & & & & & & Effects & & \\
\hline & & Quality & Consistency & Directness & HTO & no HTO & & Quality & Importance \\
\hline \multicolumn{10}{|c|}{ Range of motion (6) } \\
\hline & observational & $\begin{array}{l}\text { no serious } \\
\text { limitations }\end{array}$ & $\begin{array}{l}\text { no important } \\
\text { inconsistency }\end{array}$ & direct & 251 & 251 & $\begin{array}{l}4 / 6 \text { studies no } \\
\text { difference }\end{array}$ & low & critical \\
\hline \multicolumn{10}{|c|}{ Knee clinical scores (9) } \\
\hline & observational & $\begin{array}{l}\text { no serious } \\
\text { limitations }\end{array}$ & $\begin{array}{l}\text { no important } \\
\text { inconsistency }\end{array}$ & direct & & & & low & critical \\
\hline HSS (5/9) & & & & & 212 & 212 & $\begin{array}{l}5 / 5 \text { studies no } \\
\text { difference }\end{array}$ & & \\
\hline KSS (5/9) & & & & & 175 & 176 & $\begin{array}{l}4 / 5 \text { study no } \\
\text { difference }\end{array}$ & & \\
\hline other $(3 / 9)$ & & & & & 106 & 105 & $\begin{array}{l}2 / 3 \text { studies no } \\
\text { difference }\end{array}$ & & \\
\hline \multicolumn{10}{|c|}{ Revision surgery because of (a)septic loosening ( 8 ) } \\
\hline & observational & $\begin{array}{l}\text { no serious } \\
\text { limitations }\end{array}$ & $\begin{array}{l}\text { no important } \\
\text { inconsistency }\end{array}$ & direct & 298 & 296 & $\begin{array}{l}8 / 8 \text { studies no } \\
\text { difference }\end{array}$ & low & critical \\
\hline
\end{tabular}

found that more tibial tuberosity osteotomies were performed. These additional procedures may contribute to a significantly prolonged operation time for patients receiving TKA after prior osteotomy in three out of four studies. Many surgeons feel that intra-operative factors such as duration of the procedure may lead to inferior outcome after knee replacement. Earlier a logistic regression analysis showed that superficial infection was highly correlated with deep wound infection, which is a big threat to a successful outcome following knee joint replacement. Longer operating time, however, was no predictor of wound infection in 1181 patients undergoing TKA surgery [32]. Exposure difficulties and alterations in knee anatomy may compromise precision and accuracy of the surgical technique [31]. Especially tibial component fixation may be an issue after osteotomy due to the loss of metaphyseal bone stock. A revision tibial component with a canal-filling stem will increase the mechanical stability of tibial fixation [33]. On the other hand, a stemmed implant may prevent accurate placement of the tibial tray due to the asymmetric positioning of the medullary canal after HTO. Previous osteotomy may also influence patellar tracking leading to subluxation or rotatory instability. Malalignment and instability are major causes of early failure, and most revisions are performed within 5 years of primary arthroplasty [34]. After a median follow-up of 5 years we found no significant differences in TKA failure for the patients receiving TKA after previous osteotomy compared to primary TKA in all eight studies reporting on revision surgery. All studies presented in our review reported on primary knee prostheses, and did not describe the use of revision components. Earlier, a matched radiosteriometric study also showed no difference in failure rate after 10 years for primary knee components in patients with or without prior HTO [24]. Substantial improvements in the scores for physical health, such as those for pain and physical functioning seem to take place within the first 3 to 6 months after primary knee joint replacement, and studies with longer-term follow-up describe a lasting effect [35]. All six studies that discussed knee motion reported less range of motion with a median of $10^{\circ}$ for patients receiving TKA after osteotomy compared to primary TKA patients. Two studies even noted significant inferior results. However, a multivariate analysis suggested that when determining the success of knee arthroplasty surgery ROM is far less important than overall function [36]. At mid-term follow-up this review could not detect any significant differences between both groups for overall function evaluated by standard knee clinical scores in eight out of nine studies.

Surgical treatment options for younger patients with unicompartmental OA of the knee remain controversial. Arthroplasty may have adverse effects. In an update study of data from the Swedish Knee Arthroplasty Register younger age was associated with an increased risk of prosthetic revision [37]. The cumulative revision rate for unicompartmental arthroplasty (UKA) was even higher than for TKA, and after removal of UKA loss of bone stock required significantly more osseous reconstructions in 
total knee revision compared with TKA after HTO [26,37]. One of the main reasons to perform HTO is delaying arthroplasty. The present review shows that the use of HTO postpones primary TKA for a median of 7 years in this subgroup of patients. This may be particular beneficial for patients with early onset knee OA, whose primary TKA might wear out before they die if they did not have the HTO.

\section{Conclusion}

In summary our analysis represents the best available evidence on TKA after prior osteotomy, which seems to suggest that osteotomy does not compromise subsequent TKA. However, the overall low quality of evidence could not be raised by this review. Therefore, knee arthroplasty register data or multi-center high quality observational studies are needed to produce larger numbers and potentially generate higher quality of evidence to reach more solid conclusions.

\section{Competing interests}

The authors declare that they have no competing interests.

\section{Authors' contributions}

TR designed the study, acquired the data and drafted the manuscript. MR contributed substantially to the acquisition of data, carried out the statistical analysis and has been involved in interpretation of the data. AF and JV participated in the study design, and have been involved in critically revising the manuscript for important intellectual content. All authors read and approved of the final manuscript.

\section{Acknowledgements}

We would like to thank Reinoud W. Brouwer (RB) and Duncan E. Meuffels (DM) for their contribution to this manuscript.

\section{References}

I. Brouwer RW, van Raaij TM, Bierma-Zeinstra SM, Verhagen AP, Jakma TS, Verhaar JA: Osteotomy for treating knee osteoarthritis. Cochrane Database Syst Rev 2007, 18:CD004019.

2. Virolainen P, Aro HT: High tibial osteotomy for the treatment of osteoarthritis of the knee: a review of the literature and a meta-analysis of follow-up studies. Arch Orthop Trauma Surg 2004, I 24:258-6I.

3. NIH consensus statement on total knee replacement. $\mathrm{NIH}$ Consens State Sci Statements 2003, 20: I-34.

4. Haslam P, Armstrong M, Geutjens G, Wilton TJ: Total knee arthroplasty after failed high tibial osteotomy. J Arthroplasty 2007, 22:245-50.

5. Parvizi J, Hanssen AD, Spangehl MJ: Total knee arthroplasty following proximal tibial osteotomy: risk factors for failure. J Bone Joint Surg Am 2004, 86:474-79.

6. Windsor RE, Insall J, Vince KG: Technical considerations of total knee arthroplasty after proximal tibial osteotomy. J Bone Joint Surg Am 1988, 70:547-54.

7. Maier RV: What the surgeon of tomorrow needs to know about evidence-based surgery. Arch Surg 2006, I41:317-23.

8. Kral JG, Dixon JB, Horber FF, Rossner S, Stiles S, Torgerson JS, Sugerman HJ: Flaws in methods of evidence-based medicine may adversely affect public health directives. Surgery 2005, I 37:279-284.
9. Furlan $A D$, Irvin E, Bombardier C: Limited search strategies were effective in finding relevant nonrandomized studies. J Clin Epidemiol 2006, 59: I303-II.

10. Deeks J], Dinnes J, D'Amico R, Sowden AJ, Sakarovitch C, Song F, Petticrew $M$, Altman DG: Evaluating non-randomised intervention studies. Health Technol Assess. 2003, 7(27 iii-x): I-I73.

II. van Raaij TM, Bakker W, Reijman M, Verhaar JA: The effect of high tibial osteotomy on the results of total knee arthroplasty. BMC Musculoskelet Disord. 2007, 8:74.

12. Slim K, Nini E, Forestier D, Kwiatkowski F, Panis Y, Chipponi J: Methodological index for non-randomized studies (minors): development and validation of a new instrument. ANZ J Surg 2003, 73:712-16

13. van Tulder M, Furlan A, Bombardier C, Bouter L, the Editorial Board of the Cochrane Collaboration Back Review Group: Updated Method Guidelines for Systematic Reviews in the Cochrane Collaboration Back Review Group. Spine 2003, 28: I 290-I 299.

14. Atkins D, Best D, Briss PA, Eccles M, Falck-Ytter Y, Flottorp S, Guyatt GH, Harbour RT, Haugh MC, Henry D, Hill S, Jaeschke R, Leng G, Liberati A, Magrini N, Mason J, Middleton P, Mrukowicz J, O'Connell D, Oxman AD, Phillips B, Schünemann HJ, Edejer TT, Varonen H, Vist GE, Williams JW Jr, Zaza S, GRADE Working Group: Grading quality of evidence and strength of recommendations. BMJ 2004 , 328(7454): 1490.

15. Kunz R: Randomized trials and observational studies: still mostly similar results, still crucial differences. J Clin Epidemiol 2008, 6 I :207-8

16. Huang HT, Su JY, Su KN, Tien YC: Total knee arthroplasty after failed dome osteotomy. Kaohsiung J Med Sci 2002, I8:485-9I.

17. Karabatsos B, Mahomed NN, Maistrelli GL: Functional outcome of total knee arthroplasty after high tibial osteotomy. Can J Surg 2002, 45: I 16-9.

18. Meding JB, Keating EM, Ritter MA, Faris PM: Total knee arthroplasty after high tibial osteotomy. A comparison study in patients who had bilateral total knee replacement. J Bone Joint Surg Am 2000, 82: I 252-9.

19. Haddad FS, Bentley G: Total knee arthroplasty after high tibial osteotomy. J Arthroplasty 2000, I 5:597-603.

20. Nizard RS, Cardinne L, Bizot P, Witvoet J: Total knee replacement after failed tibial osteotomy. J Arthroplasty 1998 , I 3:847-53.

21. Amendola A, Rorabeck CH, Bourne RB, Apyan PM: Total knee arthroplasty following high tibial osteotomy for osteoarthritis. J Arthroplasty 1989, 4:SII-7.

22. Mont MA, Alexander N, Krackow KA, Hungerford DS: Total knee arthroplasty after failed high tibial osteotomy. Orthop Clin North Am 1994, 25:5 I5-25.

23. Walther M, Konig A, Kirschner S, Gohlke F: Results of posterior cruciate-retaining unconstrained total knee arthroplasty after proximal tibial osteotomy for osteoarthritis. A prospective cohort. Arch Orthop Trauma Surg 2000, I 20: I66-70.

24. Toksvig-Larsen S, Magyar G, Onsten I, Ryd L, Lindstrand A: Fixation of tibial component of total knee arthroplasty after high tibial osteotomy. J Bone Joint Surg Br 1998, 80:295-7.

25. Bergenudd $H$, Sahlström A, Sanzén L: Total knee arthroplasty after failed proximal tibial valgus osteotomy. J Arthroplasty 1997, 12:635-8.

26. Gill T, Schemitsch EH, Brick GW, Thornhill TS: Revision total knee arthroplasty after failed unicompartmental knee arthroplasty or high tibial osteotomy. Clin Orthop Relat Res 1995, $321: 10-8$.

27. Jackson M, Sarangi PP, Newman JH: Revision total knee arthroplasty. Comparison of outcome following primary proximal tibial osteotomy or unicompartmental arthroplasty. J Arthroplasty 1994, 9:539-42

28. Katz MM, Hungerford DS, Krackow KA, Lennox DW: Results of total knee arthroplasty after failed proximal tibial osteotomy for osteoarthritis. J Bone Joint Surg Am 1987, 69:225-33.

29. Furnes O, Espehaug B, Lie SA, Vollset SE, Engesæter LB, Havelin LI: Early failures among 7, I74 primary total knee replacements. A follow-up study from the Norwegian Arthroplasty Register 1994-2000. Acta Orthop Scand 2002, 73: I I 7-I 29.

30. Ng TT, McGory ML, Ko CY, Maggard MA: Meta-analysis in Surgery. Methods and Limitations. Arch Surg 2006, I 4 I : I I 25-30. 
31. Mason JB, Fehring TK, Estok R, Banel D, Fahrbach K: Meta-analysis of alignment outcomes in computer-assisted total knee arthroplasty surgery. J Arthroplasty 2007, 22:1097-106.

32. Saleh K, Olson M, Resig S, Bershadsky B, Kuskowski M, Gioe T, Robinson H, Schmidt R, McElfresh E: Predictors of wound infection in hip and knee joint replacement: results from a $\mathbf{2 0}$ year surveillance program. J Orthop Res 2002, 20:506-15.

33. Conditt MA, Parsley BS, Alexander JW, Doherty SD, Noble PC: The optimal strategy for stable tibial fixation in revision total knee arthroplasty. J Arthroplasty 2004, 19 (7 Suppl 2): I I3-8.

34. Callaghan JJ, O'Rourke MR, Saleh KJ: Why knees fail: lessons learned. J Arthroplasty 2004, 19(4 Suppl I):3 I-4.

35. Ethgen $O$, Bruyère $O$, Richy $F$, Dardennes $C$, Reginster JY: Healthrelated quality of life in total hip and total knee arthroplasty. A qualitative and systematic review of the literature. J Bone Joint Surg Am 2004, 86:963-74.

36. Miner AL, Lingard EA, Wright EA, Sledge CB, Katz JN, Kinemax Outcomes Group: Knee range of motion after total knee arthroplasty: how important is this as an outcome measure? J Arthroplasty 2003, 18:286-94.

37. Robertsson O, Knutson K, Lewold S, Lidgren L: The Swedish Knee Arthroplasty Register 1975-1997. Acta Orthop Scand 200I, 72:503-13.

\section{Pre-publication history}

The pre-publication history for this paper can be accessed here:

http://www.biomedcentral.com/1471-2474/10/88/pre

pub

Publish with Biomed Central and every scientist can read your work free of charge

"BioMed Central will be the most significant development for disseminating the results of biomedical research in our lifetime. "

Sir Paul Nurse, Cancer Research UK

Your research papers will be:

- available free of charge to the entire biomedical community

- peer reviewed and published immediately upon acceptance

- cited in PubMed and archived on PubMed Central

- yours - you keep the copyright 